blue and bloated, as described by Dornhorst (1955) and Scadding (1963). The incidence of right ventricular hypertrophy in those with the radiological emphysema pattern is seen to be about the same at $17 \%$, but in cases where a postmortem examination has been made the degree of hypertrophy was relatively slight and less marked than in those chronic bronchitics with the large hilar but normal lung vessels.

The incidence of widespread emphysema can be studied in conditions other than chronic bronchitis, particularly in cases of possible industrial pulmonary disease. A review of 400 cadmiumworkers failed to show a significant number with the emphysema pattern, though some had respiratory function studies indicating airways obstruction (Bonnell, 1955). A review of 400 coalminers seeking compensation was studied by Caplan et al. (1966); here the incidence of the radiographic emphysema pattern was small, but was higher in those with the lower categories of nodulation. This suggests that the focal emphysema of coal-miners does not give rise to widespread emphysema with air-trapping, and accounts for the difficulty found in trying to correlate the nodular shadows with disability.

Finally, there are other spheres in which radiology can be of value in epidemiological surveys, such as the incidence of hiatus hernia or of rheumatoid arthritis. In this last context it is worth noting that the percentage of $x$-ray-positive cases showing clinical manifestations of this disease will be increased from $75 \%$ to $91 \%$ if the metatarsal heads are radiographed as well as the hands and wrists, even if there are no symptoms referable to the feet (Thould and Simon, 1966).

\section{Summary and Conclusions}

There is a definite place for radiology in trials of drugs in the treatment of pulmonary tuberculosis and in some epidemio- logical surveys, particularly in coal-miners and certain other workers in industry. It is also of value in surveys of patients with chronic bronchitis, for patients showing an emphysema pattern have a much worse prognosis than those whose chest radiograph is normal. Another group with large hilar but no narrowing of the mid-lung vessels is also a suitable one for study.

\section{REFERENCES}

Bonnell, J. A. (1955). Brit. F. industr. Med., 12, 181.

Burrows, B., Niden, A. H., Barclay, W. R., and Kasick, J. E. (1965). Am. Rev. Resp. Dis., 91, 521.

Caplan, A. (1962). Ibid., 19, 171.

Reid, L., and Simon, G. (1966). Clin. Radiol. In press.

Dornhorst, A.' C. (1955). Lancet, 1, 1185.

Eade, A. W. T., Harrison, G. K., Large, S. E., Mackay-Dick, J., Reid, L., and Riddell, R. W. (1959). Thorax, 14, 104.

Fletcher, C. M. (1964). Meth. Inform. Med., 3, 98. Jones, N. L., Burrows, B., and Niden, A. H. (1964). Am. Rev. Resp. Dis., $90,1$.

Fulton, R. M., Hutchinson, E. C., and Jones, A. M. (1952). Brit. Heart f., 14, 413 .

Garland, L. H. (1950). Amer. 7. Roentgenol., 64, 32.

Medical Research Council (1960). Short Questionary on Respiratory Symptoms.

(1965). Lancet, 1, 775.

Millard, J. (1965). M.D. thesis. Univ. London.

Reid, L., and Millard, F. J. C. (1964). Clin. Radiol., 15, 307.

Rivers, D., Wise, M. E., King, E. J., and Nagelschmidt, G. (1960). Brit. f. industr. Med., 17, 87.

Scadding, J. G. (1963). Brit. med. F., 2, 1425.

Simon, G. (1964). Clin. Radiol., 15, 293.

- and Galbraith, H.-J. B. (1953). Lancet, 2, 850. and Medvei, V. C. (1962). Thorax, 17, 5.

Simpson, T., Heard, B., and Laws, J. W. (1963). Thorax, 18, 361.

Thould, A. K., and Simon, G. (1966). Ann. rheum. Dis. In press.

W.H.O. (1960). Bull. Wld Hith Org., 23, 543.

Veterans Administration (1958). Transactions of 17th Conference of the Veterans Administration on the Chemotherapy of Tuberculosis, p. 481.

Yerushalmy, J., Garland, L. H., Harkness, J. T., Hinshaw, H. C., Miller, E. R., Shipman, S. J., and Zwerling, H. B. (1951). Amer. Rev. Tuberc., 64, 225.

\title{
Cough Seizures in Patients with Cerebral Lesions
}

\author{
J. A. MORGAN-HUGHES,* B.A., M.D., B.CHIR., M.R.C.P.
}

Brit. med. Ғ., 1966, 2, 494-494

Since the observations of Charcot (1876) it has been recognized that prolonged coughing may sometimes be associated with a transient disturbance of cerebral function. Two cases were originally described, one patient experiencing brief vertiginous episodes, and the other unconsciousness with clonic movements of the face and arm. Charcot concluded that the attacks were due to irritation of the laryngeal nerves, a theory which was accepted in a modified form by many subsequent writers (Krishaber, 1882 ; Getchell, 1896).

McBride (1884) was the first to suggest that the symptoms were caused by cerebral anoxia. He believed that the increase in intrathoracic pressure produced during a paroxysm of coughing hindered the return of venous blood to the heart, thereby causing a fall in cardiac output. Little attention was paid to this idea, however, until Wilkins and Friedland (1944) recorded a diminution in the venous return and cardiac output of healthy subjects when performing the Valsalva manœuvre.

Sharpey-Schafer (1953a, 1953b) elegantly demonstrated the haemodynamic effects of prolonged coughing. With the use of capacitance manometers, he recorded intrathoracic, intracardiac, venous, and arterial pressures in 40 healthy subjects

* Institute of Neurology, Queen Square, London. and in 27 patients with a history of cough syncope. There was no qualitative difference between the effects of coughing in the two groups, the circulatory changes being proportional to the violence of the cough. Both continuous and intermittent coughing were accompanied by a sudden increase in intrathoracic pressure followed by a fall in systemic arterial pressure, unconsciousness usually occurring during the period of hypotension observed at the end of the paroxysm.

It has often been suggested, however, that other factors may be equally important in the production of cough seizures. Baker (1949) spoke of a "cerebral susceptibility," and O'Doherty (1953), who described five cases with electroencephalographic changes, concluded that an "inherent abnormality of cortical function" must contribute to this syndrome.

The four cases described below lend support to the view that disorders of the brain and cerebral vessels may occasionally be important aetiological factors.

\section{Case 1 (No. 47288)}

A housewife aged 60 was admitted to the National Hospital under the care of Sir Charles Symonds in September 1953 with a 
nine-months history of failing vision. She had been troubled by obesity for many years, and since 1948 had suffered from chronic bronchitis. Three years before admission, when drinking a cup of tea, she began to cough and then lost consciousness without warning. She regained her senses nearly an hour later, having fractured her right ankle. Six months later two further black-outs were precipitated by coughing, unconsciousness lasting only a few minutes. In one of these attacks, however, she was incontinent of urine. For nine months she had noticed progressive visual deterioration affecting both eyes and for six months had complained of short-lived frontal headaches. On direct questioning, she stated that her sense of smell had been absent for six years and admitted to being rather forgetful during recent months.

Examination showed her to be obese and euphoric, with a moderate degree of generalized intellectual deterioration. There was bilateral anosmia. Visual acuity was reduced to $6 / 36$ in the left eye and counting fingers at 1 metre in the right eye. Testing of the visual fields revealed large bilateral central scotomata. Both optic discs were pale but the pupillary reactions were normal. There were no motor or sensory abnormalities in the limbs, the reflexes being symmetrical and the plantar responses flexor. The blood-pressure was $160 / 90 \mathrm{~mm} . \mathrm{Hg}$, the pulse was regular, and there were no cardiac murmurs. Examination of the chest revealed signs of chronic bronchitits and emphysema.

Investigations.-Skull $x$-ray films showed enlargement of the left optic foramen with thickening of the floor of the anterior fossa and upper part of the lesser wing of the sphenoid bone on the left side. An E.E.G. showed bilateral frontal slow-wave activity, more pronounced on the left side. The C.S.F. was under increased pressure and contained two lymphocytes per c.mm. with a protein of 100 $\mathrm{mg} . / 100 \mathrm{ml}$.

A large subfrontal tumour was suspected clinically and later confirmed by ventriculography.

On 17 September Mr. McKissock removed a large subfrontal meningioma, probably arising from the olfactory groove on the left side. It extended to the right of the midline and forwards to the posterior wall of the frontal sinus on each side.

The patient remained drowsy and dysphasic for a few days after the operation, but subsequently made a complete recovery. She had two major seizures, in 1955 and 1957, which were unrelated to coughing, and when last heard of in 1964 there had been no further attacks of unconsciousness, though her cough had become more troublesome in recent years.

\section{Case 2 (No. 281174)}

A clerk aged 56 was referred to the late Dr. J. St. C. Elkington at St. Thomas's Hospital in May 1951 on account of black-outs associated with coughing. He had been wounded in the chest in 1914 , and for several years had suffered from chronic bronchitis and exertional dyspnoea. In 1945 he began to have attacks of unconsciousness which occurred only during bouts of coughing. Although they were nearly always associated with prolonged paroxysms, on some occasions even a slight cough was sufficient to produce an attack. Unconsciousness usually lasted for about two minutes, but on one occasion it continued for more than an hour. In six years he had over 30 attacks, and, although usually there was no warning, a few episodes were preceded by slight tingling in the fingers of one hand. For about 12 months he had complained of infrequent occipital headaches.

On examination he was noted to be obese and plethoric. The blood-pressure was normal. There were signs of chronic bronchitis and emphysema but neurological examination was negative.

A diagnosis of cough syncope was made, and symptomatic treatment was given for his cough. The attacks continued, however, and he was subsequently admitted to St. Thomas's Hospital under the late Professor Sharpey-Schafer in February 1952. Haemodynamic studies confirmed the diagnosis of cough syncope.

Although his cough improved during the next two years, the attacks of unconsciousness gradually increased in frequency, and in January 1954 he was readmitted with evidence of recent mental deterioration. Soon after admission he had a brisk haematemesis and required a transfusion. He subsequently became drowsy and hallucinated, and was noted to have a left hemiparesis. The C.S.F. was found to be under increased pressure, with 17 lymphocytes per c.mm. and a protein of $100 \mathrm{mg} . / 100 \mathrm{ml}$. Because of these findings, a diagnosis of cerebral tumour was made and a temporal decompression was performed in February 1954. His condition failed to improve, however, and he died 10 days later. Post-mortem examination revealed a large glioblastoma involving the right frontal and parietal lobes.

\section{Case 3 (No. 43820)}

A factory worker aged 50 was admitted to the National Hospital under the care of Dr. Purdon Martin in March 1953, with a twoyear history of recurrent attacks of weakness of the left arm, each attack being precipitated by a bout of coughing.

The patient's left leg had been amputated below the knee during the first world war. Following pneumonia in 1936 he had suffered from recurrent attacks of winter bronchitis. He was a heavy smoker, and for many years had noticed increasing exertional dyspnoea. In the winter of 1957 , when recovering from an attack of bronchopneumonia, he developed a severe bout of coughing, during which his speech became slurred, the left side of his face felt drawn up, and his left arm became paralysed. After about two minutes his speech and his left arm returned to normal. During the next two years he experienced 20 similar episodes of paralysis of the left arm, each attack being precipitated by a prolonged paroxysm of coughing. He stated that when he was able to terminate the cough in a shorter period of time the left arm remained normal. One month before admission, again when coughing, he developed involuntary jerking of the left arm followed after a few seconds by unconsciousness. On regaining his senses a few minutes later he noticed slight weakness of the left hand, which persisted until admission to hospital. A few days later coughing precipitated a second attack of uncontrollable jerking of the left arm, but consciousness was maintained.

On examination the blood-pressure was $160 / 90$ and the retinal vessels were narrow and tortuous. There were signs of chronic bronchitis and emphysema. In the nervous system tone and power were normal in the limbs but the left knee-jerk was brisker than the right and there was sustained patellar clonus on the left side. The right plantar response was flexor, but the left could not be elicited because of his previous amputation. Superficial sensation was slightly impaired over the left half of the face and in the left forearm and hand.

Investigations.-The skull and chest $x$-ray pictures were normal. An E.E.G. showed a slow-wave focus in the right frontotemporal region. The C.S.F. was under normal pressure with a protein of $20 \mathrm{mg} . / 100 \mathrm{ml}$. A right carotid angiogram revealed delayed filling of the anterior and middle cerebral arteries associated with extreme narrowing of the carotid siphon and the internal carotid artery throughout its length.

The patient was treated symptomatically for his cough, and when last seen, in May 1953, his attacks had ceased.

\section{Case 4 (No. A6036)}

A tailor's presser aged 62 was admitted to the National Hospital under the care of Professor Gilliatt in June 1962 complaining of weakness of the left hand and arm. He was a heavy smoker, and for 20 years had suffered from winter bronchitis with exertional dyspnoea.

Seven months before admission he suddenly lost consciousness during a bout of coughing. He recovered quickly, and there was no tongue-biting or incontinence of urine. A few days later, again during a paroxysm of coughing, he experienced uncontrollable jerking of the left arm associated with a feeling of tightness in the forearm and numbness of the fingers. Consciousness was not impaired, the attack lasting about a minute. Subsequently he continued to have similar episodes of involuntary jerking of the left arm, which occurred two or three times a day and which were always associated with a severe bout of coughing. In one attack he fell from his chair, but did not lose his senses completely. Four days before admission he developed a persistent ache in the left forearm, and two days later woke to find his left hand weak and clumsy.

On examination the blood-pressure was $155 / 95$ and the heart normal. Peripheral pulses were all present and no bruit was 
audible in the neck. There were signs of chronic bronchitis and emphysema. In the nervous system there was a left lower facial weakness, and tone was increased in the left arm with moderate weakness of all muscle groups. The deep limb reflexes were increased in the left arm but not in the leg; the plantar responses were flexor. There was some sensory loss in the left hand with impairment of position sense and two-point discrimination in the fingers.

Investigations. $-X$-ray films of the skull and chest were normal. An E.C.G. showed bilateral episodes of theta activity which were more pronounced on the right side. A right carotid angiogram showed irregular narrowing of the internal carotid artery in the region of the carotid siphon.

After 10 days in hospital power and sensation in the left arm returned to normal. At this stage the blood-pressure was artificially lowered by means of a tilt-table combined with a ganglion-blocking agent (hexamethonium). When the systolic blood-pressure fell below $100 \mathrm{~mm} . \mathrm{Hg}$ he developed weakness and hyperreflexia in the left arm associated with a dull ache in the left forearm. Complete recovery occurred on restoring the blood-pressure to normal. (A brief description of this case and further details of the tilting procedure are given by Kendell and Marshall, 1963.)

Subsequently the patient was treated symptomatically for his cough, and when last seen, in February 1964, he was free from attacks but still complained of slight stiffness in the left forearm and hand.

\section{Comment}

In Cases 1 and 2 there seems to be little doubt that the episodes of unconsciousness were related to the presence of a tumour. In Case 1 the attacks ceased after removal of the tumour, despite a worsening of her cough ; the second patient had an inoperable neoplasm and his black-outs gradually increased in frequency until just before death, although his chest symptoms were said to have improved.

In Case 1 unconsciousness lasted for an hour on one occasion. Another attack, which was shorter in duration, was accompanied by incontinence of urine, but on neither occasion were convulsive movements seen. In Case 2 the attacks were usually brief and unaccompanied by convulsive movements, the diagnosis of simple cough syncope being accepted for many years. In retrospect, however, it is interesting that the hospital notes refer to the fact that some of the attacks were preceded by paraesthesiae in the fingers of one hand.

In Case 3 coughing usually produced weakness of the arm without involuntary movements. On two occasions, however, clonic movements occurred, and in one of these attacks the movements were followed by unconsciousness. Angiography showed severe atheromatous changes in the right internal carotid artery and its branches.

In Case 4 coughing usually produced clonic movements of the arm rather than paralysis, but on one occasion it produced unconsciousness without focal features. Angiography revealed marked atheromatous narrowing in the region of the carotid siphon on the right side; transient weakness of the left arm could be reproduced artificially by lowering the systolic bloodpressure.

\section{Discussion}

The four case histories emphasize the necessity for careful neurological assessment of patients presenting with cough seizures, and they illustrate the danger of attributing such symptoms solely to the haemodynamic changes which accompany the cough. There seems to be little doubt that a haemodynamic factor was important in these patients, since they all suffered from chronic bronchitis and emphysema, and since violent coughing was usually necessary to precipitate an attack. In each case, however, there was a local cerebral lesion which appeared to be particularly susceptible to the fall in cerebral blood-flow resulting from the paroxysm. The resulting seizures differed widely in their pattern and duration. In Cases 1 and 2 the attacks of unconsciousness varied in duration from a few minutes to nearly an hour, but convulsive movements do not appear to have occurred, although not all the attacks were witnessed. In Cases 3 and 4 clonic movements of the arm occurred without loss of consciousness, a finding which suggests that the transient cerebral ischaemia gave rise to focal epileptic discharges. This is not perhaps surprising, as hypoxia is known to precipitate epilepsy and is sometimes used for this purpose in diagnostic E.E.G. laboratories (Gastaut and Meyer, 1961). It is interesting that in Case 3 coughing sometimes resulted in clonic movements but more commonly produced only weakness of the arm. This is in contrast to Case 4 , in which coughing usually gave rise to clonic movements, whereas artificially induced hypotension caused only weakness of the arm.

A review of the cases of cough syncope described in the literature suggests that cerebral abnormalities may sometimes have been present although their significance was not appreciated. Many of the patients were obese middle-aged men with evidence of generalized arterial degeneration. Whitty (1943) gave an interesting account of a 47-year-old man who was probably suffering from attacks of brain-stem ischaemia; his symptoms, consisting of blurring of vision, diplopia, giddiness, and paraesthesiae in the trunk, were sometimes precipitated by coughing but on other occasions occurred spontaneously. Electroencephalographic abnormalities have been recorded by both Whitty (1943) and O'Doherty (1953), and a previous history of head injury is mentioned in one of the cases described by Rook (1946). Although the association between cough seizures and a cerebral neoplasm has not previously been recognized, it is interesting that in one of the cases described by Baker (1949) the patient subsequently died of a bronchogenic carcinoma with suspected brain metastases.

\section{Summary}

The case of four patients who presented with cough seizures are described. Subsequent investigations revealed the presence of a cerebral tumour in two and atheromatous narrowing of the internal carotid artery in the other two. These findings illustrate the importance of excluding abnormalities of the brain and cerebral blood-vessels in patients with this disorder.

I am indebted to Sir Charles Symonds, Dr. Purdon Martin, and Professor R. W. Gilliatt for allowing me to publish cases under their care, and to the Medical Committee of St. Thomas's Hospital for permission to include Case 2. I am also indebted to Dr. John Marshall for permission to include the results of the tilting procedure in Case 4. I would like to thank Professor Gilliatt for his helpful criticism and advice.

\section{REFERENCES}

Baker, C. (1949). Guy's Hosp. Rep., 98, 132.
Charcot, J. M. (1876). Gaz. méd. Paris, 5, 588.

Gastaut, H., and Meyer, J. S. (1961). Cerebral Anoxia and the Electroencephalogram. Thomas, Springfield, Illinois.

Getchell, A. C. (1896). Boston med. surg. F., 135, 466

Getchell, A. C. (1896). Boston med. surg. F., 135, 466. 2,34

Kendell, R. E., and Marshall, J. (1963). Brit. med. 7.,

Krishaber, M. (1882). Ann. Mal. Oreil. Larynx,

O'Doherty, D. S. (1953). Neurology (Minneap.), 3, 16

Rook, A. F. (1946). Brain, 69, 138.

Sharpey-Schafer, E. P. (1953a). Brit. med. 7., 2, 860

Whit (1953b). F. Physiol. (Lond.), 122, 351 .

Wilkins, R. W., and Friedland, C. K. (1944). F. clin. Invest., 23, 939. 